\title{
One- and Two-Electron Reduction of Molecular Oxygen Based on Electrode Surface Modification in Alkaline Aqueous Media
}

\author{
Takeo OHSAKA*, Futoshi MATSUMOTO, Fusao KITAMURA \\ and Koichi TOKUDA \\ Received February 19, 1993 ; Accepted April 5, 1993
}

\section{INTRODUCTION}

Our current interest has concentrated on the electrochemical behavior of molecular oxygen $\left(\mathrm{O}_{2}\right)$ and so-called reactive oxygen species (ROS; superoxide ion $\left(\mathrm{O}_{2}^{-}\right)$, hydroxyl radical $(\cdot \mathrm{OH})$, hydrogen peroxide $\left(\mathrm{H}_{2} \mathrm{O}_{2}\right)$, etc. $)$ in both aqueous and aprotic media for several reasons, prominent among which is their role in various biological processes. ${ }^{1-5)}$ This communication reports on the preliminary results concerning the electrochemical one- and two-electron reduction of $\mathrm{O}_{2}$ based on the molecular modification of $\mathrm{Hg}$ electrode surface by hydrophobic surfactants in alkaline aqueous media.

In aqueous media two-electron reduction of $\mathrm{O}_{2}$ to hydroperoxide $\left(\mathrm{H}_{2} \mathrm{O}_{2}\right.$ or $\left.\mathrm{HO}_{2}^{-}\right)$or four-electron reduction of $\mathrm{O}_{2}$ to $\mathrm{H}_{2} \mathrm{O}$ or $\mathrm{OH}^{-}$is ordinarily observed, while one-electron reduction of $\mathrm{O}_{2}$ to $\mathrm{O}_{2}{ }^{-}$can be directly observed only in special cases, e.g., by using $\mathrm{Hg}$ electrode and making aqueous medium strongly alkaline and providing it with a hydrophobic surfactant. ${ }^{6-8)}$ In the latter case, the $\mathrm{Hg}$ electrode surface is coated with a hydrophobic monolayer in contact with aqueous medium, resulting in the chemically modified electrode system with a hydrophobic/hydrophilic interface. Such an interface, which is considered as a model biological one, will be thus used to study the molecular reactivity of $\mathrm{O}_{2}$ and $\mathrm{ROS}$ in biological processes from an electrochemical point of view.

\section{EXPERIMENTAL}

All electrochemical experiments were done at laboratory temperature $\left(20 \pm 2{ }^{\circ} \mathrm{C}\right)$ by using a standard three-electrode, one compartment configuration with a

Department of Electronic Chemistry,Interdisciplinary Graduate School of Science and Engineering, Tokyo Institute of Technology (Nagatsuta, Midori-ku, Yokohama 227, Japan)

Key Words: Molecular Oxygen, Superoxide Ion, Disproportionation, Electrode Surface Modification, $\alpha$-Quinoline ,Hydrophobic Surfactants hanging mercury drop electrode (HMDE; PAR 303, EG \& G Princeton Applied Research, area: $0.011 \mathrm{~cm}^{2}$ ) as the working electrode, a spiral platinum counter electrode and a $\mathrm{KCl}$ saturated $\mathrm{Ag} / \mathrm{AgCl}$ reference electrode. Cyclic voltammetric and double potential-step chronoamperometric measurements and the analysis of the results were conducted as described previously. ${ }^{1,9,10)} \mathrm{NaOH}$ solutions of various concentrations (0.001 1 M, M $=\mathrm{mol} \mathrm{dm}^{-3}$ ) were used as supporting electrolytes, together with phosphate or carbonate buffers or KCl when necessary. $\alpha$-Quinoline (Wako Pure Chemical Industries, Ltd.) and triphenylphosphine oxide (TPPO, Aldrich) of reagent grade were used as hydrophobic surfactants. Water was purified by a Millipore Milli-Q system.


$\alpha$-Quinoline

TPPO

\section{RESULTS AND DISCUSSION}

Figure 1 shows the cyclic voltammograms for 0.1 $\mathrm{M} \mathrm{NaOH}+0.5 \mathrm{M} \mathrm{KCl}$ aqueous solutions saturated with $\mathrm{O}_{2}$ in the absence (A) and the presence (B) of $\alpha-$ quinoline of $17 \mathrm{mM}$ (close to its saturated concentration). The voltammograms obtained around $-0.14 \mathrm{~V}$ vs. $\mathrm{Ag} / \mathrm{AgCl}$ in the absence of $\alpha$-quinoline correspond to the two-electron reduction of $\mathrm{O}_{2}{ }^{6,8)}$ :

$$
\mathrm{O}_{2}+\mathrm{H}_{2} \mathrm{O}+2 \mathrm{e}^{-} \rightarrow \mathrm{OH}^{-}+\mathrm{HO}_{2}^{-}
$$

This reaction is substantially reversible on the experimental time scale used here as can be seen from the following facts: (i) the separation $\left(\Delta E_{\mathrm{p}}\right)$ of anodic and 
cathodic peak potentials $\left(E_{\mathrm{p}}{ }^{\mathrm{a}}\right.$ and $\left.E_{\mathrm{p}}{ }^{\mathrm{c}}\right)$ is ca. $30 \sim 35$ $\mathrm{mV}$ irrespective of potential scan rate (v), (ii) the ratios of anodic peak current to cathodic one $\left(i_{\mathrm{p}}{ }^{\mathrm{a}} / i_{\mathrm{p}}{ }^{c}\right)$ are

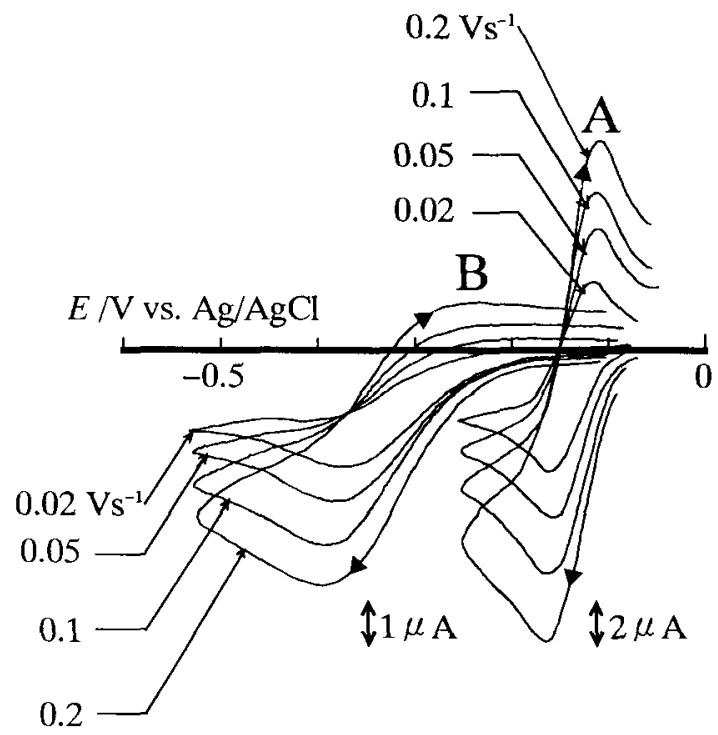

Fig. 1. Typical cyclic voltammograms obtained with HMDE (area: $0.011 \mathrm{~cm}^{2}$ ) in $\mathrm{O}_{2}$-saturated aqueous solutions containing $0.1 \mathrm{M} \mathrm{NaOH}$ and $0.5 \mathrm{M} \mathrm{KCl}$ in the absence (A) and the presence (B) of $17 \mathrm{mM} \mathrm{a-quino-}$ line. almost unity, (iii) $i_{\mathrm{p}}{ }^{c}$ is proportional to $v^{1 / 2}$ and (iv) the shift of the formal potential $\left(E^{\circ}\right)$, estimated as the average of $E_{\mathrm{p}}{ }^{\mathrm{a}}$ and $E_{\mathrm{p}}{ }^{\mathrm{c}}$, is about $-30 \mathrm{mV} /$ unit $\mathrm{pH}$ (Table 1), which is in agreement with that to be expected theoretically for a typical two-electron Nernstian process. These are consistent with the previous data. ${ }^{6,8)}$

Addition of $\alpha$-quinoline surfactant into the solution displaces the reduction potential of $\mathrm{O}_{2}$ toward more negative direction by ca. $200 \sim 250 \mathrm{mV}$ ( see voltammograms B ). In this case, $E^{\circ}$ could be regarded as actually independent of $\mathrm{pH}$ (or concentration of $\mathrm{NaOH}$ ) and was ca. $-0.31 \mathrm{~V}$ vs. $\mathrm{Ag} / \mathrm{AgCl}$ in agreement with literature values. ${ }^{6-8)} i_{\mathrm{p}}{ }^{\mathrm{c}}$ is about one-half that for the two-electron redction of $\mathrm{O}_{2}$ ( Table 1 ). ${ }^{11)}$ Thus, this process corresponds to one-electron reduction of $\mathrm{O}_{2}$ to $\mathrm{O}_{2}^{-6-8)}$.

$$
\mathrm{O}_{2}+\mathrm{e}^{-} \rightarrow \mathrm{O}_{2}^{-}
$$

Recently the adsorption of isoquinoline, which is a structural isomer of $\alpha$-quinoline, on $\mathrm{Hg}$ surfaces has been confirmed by in situ FT-IR spectroscopy, ${ }^{12,13)}$ electrocapillary methods, ${ }^{14)}$ ellipsometry, ${ }^{15)}$ potentialstep techniques, ${ }^{16)}$ etc. Thus, it can be thought that $\alpha-$ quinoline adsorbs strongly to HMDE surface and displaces the water molecules from the surface, rendering

Table 1 Cyclic voltammetric data for one- and two-electron reduction of $\mathrm{O}_{2}$ at HMDE in the absence and the presence of $\alpha$-quinoline ${ }^{\text {a) }}$

$\begin{aligned} & \text { Supporting } \\ & \text { Electrolytes }\end{aligned} \frac{i_{\mathrm{p}}{ }^{\mathrm{c}}\left(\mathrm{O}_{2} / \mathrm{HO}_{2}^{-}\right)^{\mathrm{b})}}{\mu \mathrm{A} \mathrm{cm}{ }^{-2}} \frac{i_{\mathrm{p}}{ }^{\mathrm{c}}\left(\mathrm{O}_{2} / \mathrm{O}_{2}^{-}\right)^{\mathrm{c})}}{\mu \mathrm{A} \mathrm{cm}}-\frac{E^{\circ}}{\mathrm{V}\left(\mathrm{O}_{2} / \mathrm{HO}_{2}^{-}\right)^{\mathrm{b})}}$

$0.001 \mathrm{M} \mathrm{NaOH}$

$0.5 \mathrm{M} \mathrm{KCl}, \mathrm{pH}$ ca. 11

$0.01 \mathrm{M} \mathrm{NaOH}$

$0.5 \mathrm{M} \mathrm{KCl}, \mathrm{pH}$ ca. 12

$0.1 \mathrm{M} \mathrm{NaOH}$

$0.5 \mathrm{M} \mathrm{KCl}, \mathrm{pH}$ ca. 13
786

773

845
500

389

395
$-0.080$

$-0.107$

$-0.140$

a) Concentration of $\alpha$-quinoline: $17 \mathrm{mM}$, potential scan rate: $0.1 \mathrm{Vs}^{-1}$.

b) For two-electron process (Eq.(1)).

c) For one-electron process (Eq.(2)). 
the access of the solvent to $\mathrm{O}_{2}^{-}$formed in the hydrophobic layer difficult. Consequently, one can actually realize one-electron redox process of the $\mathrm{O}_{2} / \mathrm{O}_{2}^{-}$redox couple, which has usually been observed in aprotic solvents ${ }^{4)}$, even in aqueous media. The similar results were also obtained using TPPO in place of $\alpha-$ quinoline as a hydrophobic surfactant, except that in the former case the $i_{\mathrm{p}}{ }^{a} / i_{\mathrm{p}}{ }^{\mathrm{c}}$ value at a given $v$ is a little smaller than that in the latter case.

In contrast to the $\mathrm{O}_{2} / \mathrm{HO}_{2}{ }^{-}$process ( Eq.(1)), $i_{\mathrm{p}}{ }^{\mathrm{a}} / i_{\mathrm{p}}{ }^{\mathrm{c}}$ is much smaller than unity and strongly depends on $v$ : it increases with increasing $v$. This fact together with the previous results ${ }^{6-8)}$ demonstrates the regeneration of $\mathrm{O}_{2}$ via the homogeneous disproportionation of $\mathrm{O}_{2}^{-} \cdot{ }^{6-8)}$

$$
2 \mathrm{O}_{2}^{-}+2 \mathrm{H}_{2} \mathrm{O} \stackrel{k_{\text {disp }}}{\rightarrow} \mathrm{H}_{2} \mathrm{O}_{2}+\mathrm{O}_{2}+2 \mathrm{OH}^{-}
$$

Double potential-step chronoamperometry (DPSCA) ${ }^{9)}$ was applied to estimate the rate constant $\left(k_{\text {disp }}\right)$ of disproportionation by assuming that the adsorption of $\alpha$-quinoline on the HMDE surface simply results in

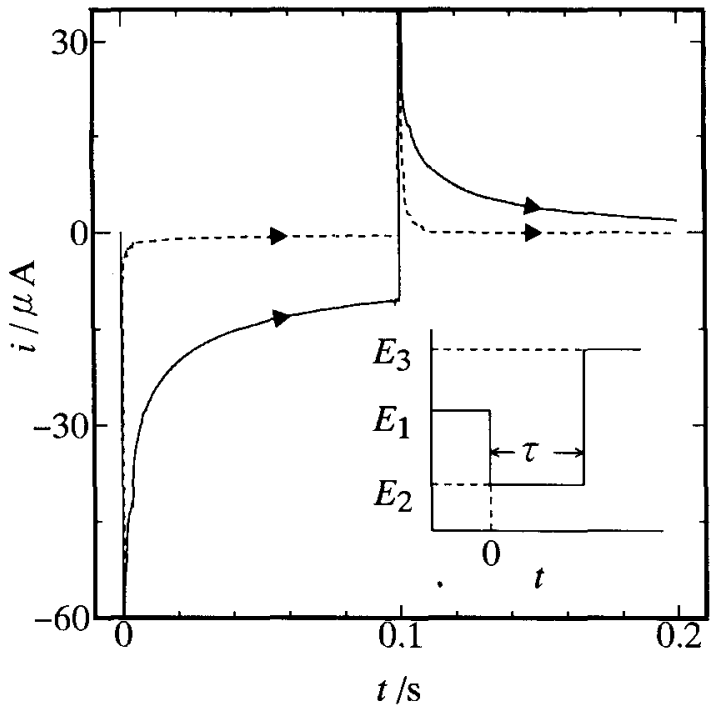

Fig. 2. Typical DPSCA responses obtained with HMDE (area: $0.011 \mathrm{~cm}^{2}$ ) in $\mathrm{O}_{2}$-saturated (solid line) and deaerated (dashed line) aqueous solutions containing $0.01 \mathrm{M} \mathrm{NaOH}, 0.5 \mathrm{M} \mathrm{KCl}$ and $17 \mathrm{mM} \alpha$-quinoline. The inset represents the potential-step mode used in the DPSCA measurement. $E_{1}=-0.03 \mathrm{~V}, E_{2}=-0.55$ $\mathrm{V}$ and $E_{3}=-0.02 \mathrm{~V}$ vs. $\mathrm{Ag} / \mathrm{AgCl}$. Potential-step width $(\tau): 100 \mathrm{~ms}$. the shift of $\mathrm{O}_{2}$ reduction from two-electron process to one-electron process. A typical example of such measurements is shown in Fig.2. The value of $k_{\text {disp }}$ was estimated to be $(4 \pm 1) \times 10^{3} \mathrm{M}^{-1} \mathrm{~s}^{-1}$ in $0.01 \mathrm{M} \mathrm{NaOH}+$ $0.5 \mathrm{M} \mathrm{KCl}$ solution ( $\mathrm{pH} 12$, concentration of $\mathrm{O}_{2}$ : $\left.1.25 \times 10^{-3} \mathrm{M}^{6)}\right)$. Our value is significantly larger than that ( $(6 \pm 1) \mathrm{M}^{-1} \mathrm{~s}^{-1}$ ) obtained by polarography at $\left.\mathrm{pH}>12,{ }^{6}\right)$ probably suggesting that in the present case the disproportionation of $\mathrm{O}_{2}^{-}$could also be catalyzed by trace amounts of impurities. A detailed study concerning the mechanism is currently under way.

The rates of the disproportionation of $\mathrm{O}_{2}^{-}$have been well-known to strongly depend on the properties (e.g., $\mathrm{pH}$, ionic strength ) of aqueous media in which

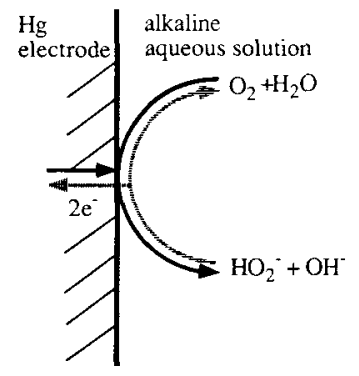

(A) two-electron process

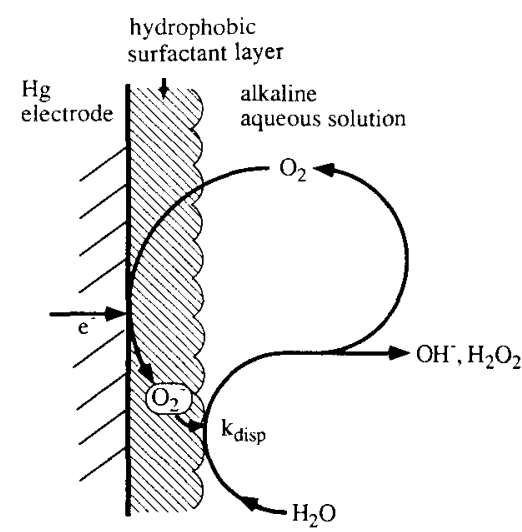

(B) one-electron process

Scheme 1 Schematic depiction of the electrochemical reduction of $\mathrm{O}_{2}$ on (A) bare $\mathrm{Hg}$ electrode and (B) $\mathrm{Hg}$ electrode coated with a hydrophobic surfactant layer in alkaline aqueous media. $k_{\text {disp }}$ represents the rate constant of homogeneous disproportionation of $\mathrm{O}_{2}^{-}$. 
its kinetics is investigated. ${ }^{8)}$ Further we can see that the $k_{\text {disp }}$ values obtained in the present and previous studies $\left.^{6}\right)$ in aqueous media are significantly larger than those ( typically $10^{-4}-10^{-2} \mathrm{M}^{-1} \mathrm{~s}^{-1}$ ) in aprotic media such as acetonitrile and dimethylformamide. ${ }^{17)}$ This makes us speculate that the effective rates for the disproportionation of $\mathrm{O}_{2}^{-}$, which might occur in the aprotic, hydrophobic region, e.g., of cell membranes delimited by the two phospholipid layers, would be much smaller than those in the hydrophilic region composed of bulk water and that the length of the diffusion path of $\mathrm{O}_{2}^{-}$is thus longer in the former case. These may be closely associated with the more compelling need for superoxide dismutases ( SODs ), which catalyze the disproportionation of $\mathrm{O}_{2}^{-}$, under biological environments.

In conclusion, the one- and two-electron reduction of $\mathrm{O}_{2}$ in alkaline aqueous media can be controlled based on the molecular modification of HMDE surface by hydrophobic surfactants such as $\alpha$-quinoline and TPPO ( Scheme 1 ). The present study reconfirms the previous ones ${ }^{6,7)}$ and further suggests that the present electrode system involving a hydrophobic/hydrophilic interface might provide a model biological interface to examine the biomolecular reactivity of $\mathrm{O}_{2}$ and ROS in aqueous media.

The present work was partially supported by a Grantin-Aid for Scientific Research from the Ministry of Education, Science and Culture, Japan, the Nissan Science Foundation and the Nakatani Electric Measuring Technology Foundation.

\section{REFERENCES}

1) T. Ohsaka, T. Watanabe, F. Kitamura, N. Oyama and

K. Tokuda, J.Chem.Soc.,Chem. Commun., 487(1991).
2) T. Ohsaka, T. Watanabe, F. Kitamura, N. Oyama and K. Tokuda, J.Chem.Soc.,Chem. Commun., 1072(1991).

3) N. Oyama, S. Ikeda, M. Suzuki and T. Ohsaka,

Electroanalysis, $\underline{3}$, 665(1991)

4) T. Ohsaka, M. Tushima and K. Tokuda, Bioelectrochem. \& Bioenerg., in press.

5) T. Watanabe, K. Tokuda and T. Ohsaka, Denki Kagaku, 60, 455(1992).

6) J. Divisek and B. Kastening, J.Electroanal,Chem., 65,603((1975).

7) J. Chevalet, F. Rouelle, L. Gierst and J.P. Lambert, J.Electroanal.Chem., 39, 201(1972).

8) D.T. Sawyer and E.T. Seo, Inorg.Chem., 16, 499(1977).

9) M.K. Hanafey and C.N. Reilley, Anal.Chem., 50, 116(1978).

10) T. Ohsaka, T. Sotomura, H. Matsuda and N. Oyama, Bull. Chem. Soc. Jpn., 56, 3065(1983).

11) It should be noted that $i_{\mathrm{p}}{ }^{\mathrm{c}}$ is not exactly one-half that for the two-electron process, reflecting the possible follow-up chemical reactions of $\mathrm{O}_{2}^{-}$(e.g., disproportionation ( Eg.(3) )).

12) D.J. Blackwood and S. Pons, J.Electroanal.Chem., 247, 277(1988).

13) F. Matsumoto, F. Kitamura, K. Tokuda and T. Ohsaka, manuscript in preparation.

14) C. Buess-Herman, N. Vanlaethem-Meuree, G. Quarin and L. Gierst, J.Electroanal.Chem., 123, 21(1981).

15) M.W. Humphreys and R.J. Parsons,J.Electroanal. Chem., 82, 369(1977).

16) C. Buess-Herman, C. Frank, C. Gierst and L. Gierst, Electrochim. Acta, 31, 965(1986)

17) M. Tsushima, K. Tokuda and T. Ohsaka, J.Chem.Soc, Perkin Trans. 2, submitted. 